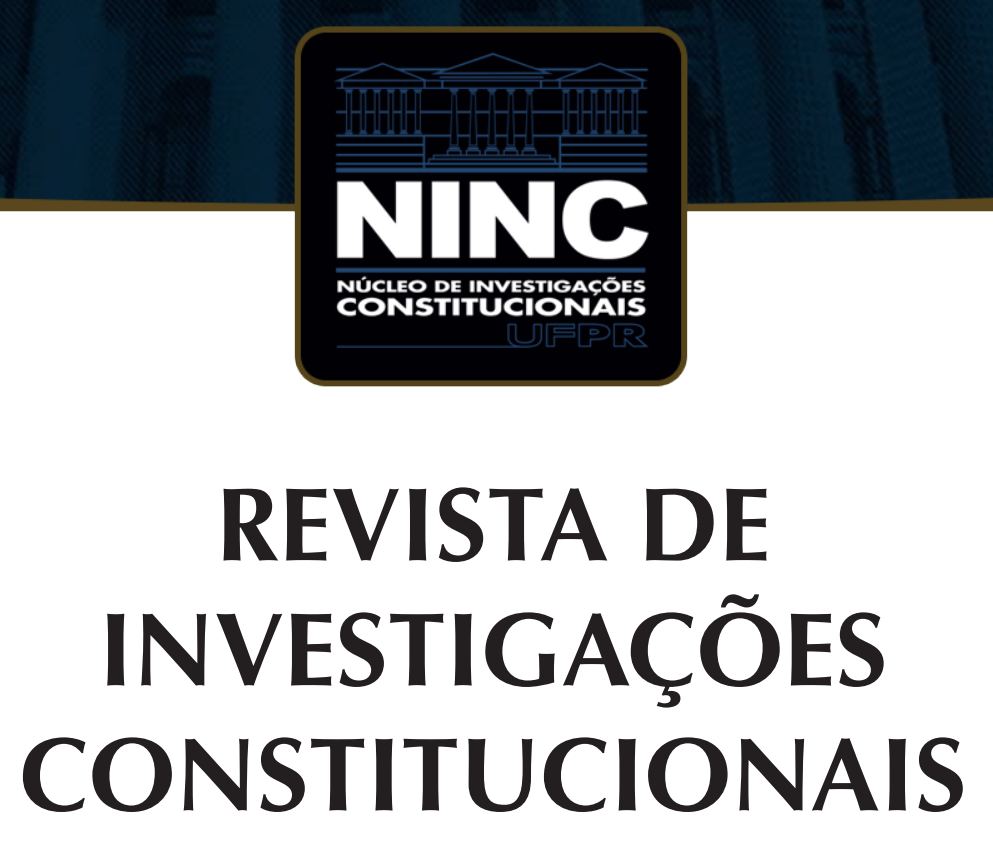

JOURNAL OF CONSTITUTIONAL RESEARCH

vol. 8 | n. 2 | maio/agosto 2021 | ISSN 2359-5639 | Periodicidade quadrimestral Curitiba | Núcleo de Investigações Constitucionais da UFPR | www.ninc.com.br 


\title{
O controle de constitucionalidade e a atuação do Supremo Tribunal Federal na proteção das minorias: análise crítica da ADC n 41 (cotas raciais em concursos públicos)*
}

\section{The constitutionality control and the role of Brazilian Federal Supreme Court regarding minorities's protection: critical analysis of ADC n' 41 (racial quotas in public tenders)}

\author{
SABRINA SANTOS LIMA ${ }^{1, * *}$ \\ ' Universidade de Santa Cruz do Sul (Santa Cruz do Sul, Rio Grande do Sul, Brasil) \\ sa._94@hotmail.com \\ https://orcid.org/0000-0003-2863-1755 \\ MÔNIA CLARISSA HENNIG LEAL 1,*** \\ ' Universidade de Santa Cruz do Sul (Santa Cruz do Sul, Rio Grande do Sul, Brasil) \\ moniah@unisc.br \\ http://orcid.org/0000-0002-3446-1302 \\ Recebido/Received: 29.02.2020 / February $29^{\text {th }}, 2020$ \\ Aprovado/Approved: 24.05.2021 / May 24 ${ }^{\text {th }}, 2021$
}

\begin{abstract}
Como citar esse artigo/How to cite this article: LIMA, Sabrina Santos; LEAL, Mônia Clarissa Hennig. O controle de constitucionalidade e a atuação do Supremo Tribunal Federal na proteção das minorias: análise crítica da ADC no 41 (cotas raciais em concursos públicos). Revista de Investigações Constitucionais, Curitiba, vol. 8, n. 2, p. 507-528, maio/ago. 2021. DOI: $10.5380 /$ rinc.v8i2.72003.

"Este artigo foi realizado com apoio da Coordenação de Aperfeiçoamento de Pessoal de Nível Superior - Brasil (CAPES) - Código de Financiamento 001, e foi financiado pelo CNPq, pela FAPERGS, e pelo CIEPPP (financiado pelo FINEP).

* Doutoranda no Programa de Pós-Graduação Stricto Sensu em Direitos Sociais e Políticas Públicas da Universidade de Santa Cruz do Sul (Santa Cruz do Sul-RS, Brasil), na linha de pesquisa Dimensões Instrumentais das Políticas Públicas. Bolsista PROSUC/ CAPES. Mestre em Direito pela Universidade de Santa Cruz do Sul - UNISC, na linha de pesquisa Constitucionalismo Contemporâneo, com bolsa PROSUC/CAPES. Professora de Direito Penal na Faculdade Dom Alberto. Servidora Pública do Município de Santa Cruz do Sul/RS. Membro do Grupo de Pesquisa "Jurisdição Constitucional aberta: uma proposta de discussão da legitimidade e dos limites da jurisdição constitucional - instrumentos teóricos e práticos", vinculado ao CNPq e coordenado pela professora Pós-Dra. Mônia Clarissa Hennig Leal. E-mail: sa._94@hotmail.com.

**** Professora do Programa de Pós-Graduação em Direito - Mestrado e Doutorado da Universidade de Santa Cruz do Sul (Santa Cruz do Sul-RS, Brasil), onde ministra as disciplinas de Jurisdição Constitucional e de Políticas Públicas, respectivamente. Doutorado em Direito pela Universidade do Vale do Rio dos Sinos - Unisinos (São Leopoldo, RS, Brasil), com pesquisas realizadas junto à Ruprecht-Karls Universität Heidelberg, na Alemanha. Pós-Doutorado na Ruprecht-Karls Universität Heidelberg (Alemanha). Coordenadora do Grupo de Pesquisa "Jurisdição Constitucional aberta", vinculado ao CNPq. Bolsista de produtividade em pesquisa do CNPq. E-mail: moniah@unisc.br.
\end{abstract}


Resumo

Considerando os recentes debates acerca das políticas públicas relativas a ações afirmativas, como é o caso das cotas raciais, questiona-se: como se dá a atuação do Supremo Tribunal Federal (STF) no que tange à proteção das minorias, tomando-se como base a decisão proferida na $A D C n^{\circ} 41$ ? Utiliza-se, na estruturação e organização do texto, o método dedutivo, baseado em pesquisa bibliográfica e em análise de caso. Para tanto, inicialmente são tecidos apontamentos quanto ao controle de constitucionalidade e de sua função estratégica na ordem jurídico-constitucional, para, então, averiguar-se os desdobramentos das políticas de ações afirmativas e o papel do STF na proteção das minorias; por fim, analisa-se criticamente a decisão recentemente proferida no âmbito da $A D C n^{\circ} 41$, que se refere à constitucionalidade das cotas para negros em concursos públicos. Conclui-se que há a adoção de uma postura de proteção às minorias, por parte do STF, o qual adota um conceito de minorias não relacionado com a questão numérica, mas sim com o reconhecimento de um grupo de pessoas estigmatizado histórica e socialmente, vítima de uma discriminação estrutural e que, portanto, merece ser objeto de proteção por parte de políticas públicas de inclusão social e de não-discriminação.

Palavras-chave: Supremo Tribunal Federal; políticas públicas de inclusão social e de não-discriminação; ações afirmativas; minorias; cotas raciais.

\section{Abstract}

Regarding the recent debates about the public policies related to affirmative actions, as is the case of racial quotas, the following problem arises: how does the Brazilian Federal Supreme Court act in regard to the protection of minorities, based on the decision rendered in $A D C 41$ ? The deductive method, based on bibliographic research and case analysis, is used in the structuring and organization of the text. In order to achieve the proposed objective, ideas about constitutionality control and its strategic function in the juridical-constitutional order, are first approached, and then the affirmative action policies are analyzed, such as the role of the Brazilian Supreme Court in the protection of minorities. Finally, the decision recently issued under $A D C 41$, which refers to the constitutionality of quotas for black people in public tenders, is analyzed critically. It concludes that the STF adopts a position of protection to minorities, and also adopts a concept of minorities not related to the numerical issue, but with the recognition of a group of people stigmatized historically and socially, which is a victim of structural discrimination, and therefore deserves to be protected by public policies of social inclusion and non-discrimination.

Keywords: Brazilian Federal Supreme Court; public policies for social inclusion and no-discrimination; affirmative actions; minorities; racial quotas.

\section{SUMÁRIO}

1. Introdução; 2. Apontamentos sobre o controle de constitucionalidade: do seu nascimento à sua aplicação no direito brasileiro; $\mathbf{3}$. As políticas de ação afirmativa e a atuação do Supremo Tribunal Federal na proteção das minorias; 4. Reserva de vagas para negros em concursos públicos como estratégia de inclusão social e de proteção de minorias: análise crítica da ADC 41; 5. Conclusão; 6 . Referências.

\section{INTRODUÇÃO}

Principalmente a partir da promulgação da Constituição Federal de 1988, notou-se um avanço no sentido de buscar efetivar-se o que se convencionou chamar de igualdade material, isto é, uma igualdade que não se basta nas formalidades e no âmbito jurídico, ultrapassando essa seara e indo ao encontro da realidade fática, buscando, em última análise, concretizar a igualdade na prática, considerando-se as diferenças existentes entre os indivíduos, no caso das cotas raciais, especificamente, considerando-se as diferenças sob o aspecto de uma dimensão social. Nesse cenário, em razão do 
reconhecimento da existência de grupos minoritários ${ }^{1}$, que não possuem as mesmas condições e oportunidades que os demais, passou-se a falar, de forma mais acentuada, em políticas de ações afirmativas, que visam justamente alcançar o equilíbrio (ou compensar desigualdades faticamente existentes) em relação a determinado grupo.

De forma específica, o presente trabalho foca na questão dos negros, que, muito embora não sejam minoria em números, o são em razão do racismo, bem como em razão de uma desigualdade social e de oportunidades presente na sociedade brasileira. No que se refere a essa questão específica, algumas políticas públicas já foram implementadas no intuito de buscar a compensação dessa desigualdade ainda existente, bem como no intuito de procurar igualar as condições e oportunidades entre brancos e negros, sendo elas a política de cotas para o ingresso em universidades, e a política de cotas para concursos públicos da administração pública federal. A última foi instituída por meio de uma Lei Federal, a qual vinha sendo objeto de constante divergência entre juízes e Tribunais, motivo pelo qual se ajuizou uma Ação Declaratória de Constitucionalidade perante o Supremo Tribunal Federal. A ação de controle concentrado foi sentenciada no ano de 2017 e trouxe inúmeros argumentos, em uma forte e robusta fundamentação, abarcando temas como a constitucionalidade das ações afirmativas e o reconhecimento da existência de um racismo estrutural no Brasil.

A partir daí exsurge a problemática a ser trabalhada ao longo deste artigo, calcada no seguinte questionamento: como se dá a atuação do Supremo Tribunal Federal no que tange à proteção das minorias, com base na decisão proferida na ADC n० 41 ? Na pretensão de responder o problema suscitado, utilizar-se-á o método dedutivo, partindo-se de uma perspectiva geral para a particular, através da pesquisa bibliográfica e análise jurisprudencial de uma decisão recente proferida pelo STF. Esse tema merece reflexão e estudo em razão da função contramajoritária atribuída ao Supremo, assim como em razão da necessidade de se falar de políticas de ações afirmativas, que vem ao encontro das determinações constitucionais e do princípio da igualdade material, mas que ainda são objeto de discussão.

Desse modo, para alcançar o objetivo pretendido, abordam-se, num primeiro momento, aspectos pontuais e relevantes a respeito do controle de constitucionalidade, expondo-se a sua origem histórica e a sua aplicação no direito brasileiro. A partir disso, trata-se da questão das políticas de ação afirmativa e do papel contramajoritário do STF, e, num momento final, analisa-se, criticamente, a decisão proferida, que trata das cotas raciais para concursos públicos da administração pública federal, a partir da qual será possível verificar de que forma o Supremo Tribunal Federal exerce a proteção das minorias.

\footnotetext{
Frisa-se, desde logo, que o termo "minoria" não está atrelado, necessariamente, a uma ideia de quantidade numérica, mas sim com a noção de desigualdade (social, econômica, histórica e cultural, por exemplo), conforme será visto no decorrer deste trabalho.
} 


\section{APONTAMENTOS SOBRE O CONTROLE DE CONSTITUCIONALI- DADE: DO SEU NASCIMENTO À SUA APLICAÇÃO NO DIREITO BRASILEIRO}

Num primeiro momento, é importante ter claro que a conformação da Constituição, enquanto documento jurídico rígido e formal-escrito, se deu na Idade Moderna, mais precisamente a partir da Revolução Francesa de 1789, a qual foi marcada pela derrubada do Antigo Regime e consequente ascensão da classe burguesa, que deu origem ao Estado liberal'2. Já o desenvolvimento e o fortalecimento da jurisdição constitucional, por sua vez, desenvolvem-se em momento posterior, estando intimamente ligados à evolução dos acontecimentos históricos vivenciados em cada sociedade, não surgindo como decorrência necessária da consolidação da figura da Constituição. Na França, por exemplo, o Poder Judiciário se destacou tardiamente, em comparação com os Estados Unidos. Esse destaque, contudo, não está vinculado ao exercício do controle de constitucionalidade, haja vista que na França esse mecanismo não é realizado pelo Judiciário, mas sim por um órgão de caráter político ${ }^{3}$.

Na França, em um contexto pós Revolução Francesa, o Poder Legislativo acaba por ser sobrestimado, ao passo que o Judiciário fica em segundo plano. Prepondera o entendimento, naquele momento histórico, de que o Judiciário deve ater-se somente ao que diz a lei, sem interpretá-la ou exercer qualquer tipo de atividade hermenêutica e criativa (Escola do Empirismo Exegético), havendo, nessas circunstâncias, uma supervalorização da lei e do Poder Legislativo. O Judiciário, ali, é visto com cautela pela sociedade, tendo em vista estar conectado com o Antigo Regime e ao ideal absolutista. Deve, portanto, analisar o fato e a norma para chegar a uma conclusão, sem espaço para maiores interpretações ${ }^{4}$.

Diferente cenário pode ser percebido no contexto norte-americano, em que o Poder Legislativo é visto com mais cautela, ao passo que o Judiciário é percebido como o órgão capaz de atuar em defesa dos direitos naturais, inerentes ao homem. Isto é, no contexto norte-americano surge certa insegurança com relação ao legislador, posto que esse Poder, além de possuir forte ligação com o Parlamento britânico, poderia

\footnotetext{
LEAL, Mônia Clarissa Hennig. A Constituição como princípio: os limites da jurisdição constitucional brasileira. São Paulo: Manole, 2003, p. 1-2.

CAPPELLETTI, Mauro. O controle judicial de constitucionalidade das leis no direito comparado. 2. ed. Porto Alegre: Sergio Antonio Fabris Editor, 1992, p. 94-99. Sobre o sistema francês atual, ver: ARAÚJO, Luiz Henrique Diniz. Filtros de acesso às Cortes Constitucionais: a Questão Prioritária de Constitucionalidade e os filtros de acesso ao Conselho Constitucional Francês. Revista de Investigações Constitucionais, Curitiba, vol. 6, n. 2, p. 405-422, maio/ago. 2019; FACCHINI NETO, Eugênio; HENDGES, Carla Evelise Justino. E a França piscou: a questão prioritária de constitucionalidade e o fim do controle exclusivamente prévio de constitucionalidade. A\&C - Revista de Direito Administrativo \& Constitucional, Belo Horizonte, ano 17, n. 67, p. 153-183, jan./mar. 2017.

4 SOUZA NETO, Cláudio Pereira de; SARMENTO, Daniel. Direito constitucional: teoria, história e métodos de trabalho. Belo Horizonte: Fórum, 2012, p. 22.
} 
restringir os direitos do homem. E, dessa forma, há a compreensão de que o Judiciário poderia, e inclusive deveria, intervir com maior frequência, sempre que esses direitos se vissem ameaçados, questão que repercutiu, posteriormente - mais precisamente a partir da década de 1950 -, no desenvolvimento do ativismo judicial, fenômeno sempre marcante no sistema norte-americano. Pode-se dizer, portanto, que é nessa conjuntura que se desenvolve o controle de constitucionalidade no contexto americano, segundo o qual todo juiz estaria apto a intervir quando algum dispositivo constitucional fosse violado por ato legislativo ${ }^{5}$.

Refere-se, assim, que nos Estados Unidos o controle de constitucionalidade foi desenvolvido sob esse aspecto, ficando imortalizado com a decisão proferida no emblemático caso Marbury versus Madison ${ }^{6}$, em 1803, que aborda a possibilidade de judicial review (modelo difuso do controle de constitucionalidade). O juiz John Marshall, nesse caso, defendeu a ideia de supremacia da Constituição e, por conseguinte, sustentou que todos os atos legislativos deveriam estar em conformidade com ela, sob pena de se serem nulos. Além disso, sustentou que a tarefa de analisar e julgar se uma lei está, ou não, de acordo com a Constituição cabe aos tribunais, ao Poder Judiciário.

Verifica-se ainda que, no Estado liberal, o Poder Legislativo acaba por tornar-se o Poder de maior protagonismo e atuação (valorização da supremacia da lei). Já no Estado de Bem-Estar Social, que se desenvolve a partir do início do Século XX, tendo por fundamento uma noção de igualdade material, o Poder Executivo ganha força, na medida em que é demandado a atuar de forma positiva na prestação de direitos sociais, e não apenas se abstendo de intervir na esfera privada. Dito de outro modo, a partir da vigência do modelo de Estado de Bem-Estar Social, o Poder Executivo passa de um papel secundário para o um papel protagonista ${ }^{8}$.

\footnotetext{
5 LEAL, Mônia Clarissa Hennig. Jurisdição constitucional aberta: reflexões sobre a legitimidade e os limites da jurisdição constitucional na ordem democrática. Rio de Janeiro: Lumen Juris, 2007, p. 27-29.

6 Importante frisar que a noção de um controle de constitucionalidade, nos Estados Unidos, se desenvolveu muito antes desse caso específico (Marbury x Madison). Contudo, esse é o caso referencial do modelo americano de controle de constitucionalidade, apontado, não raramente, como o caso que deu origem ao judicial review. Assim, o julgamento do caso Marbury contribuiu para o desenvolvimento da judicial review, porém não foi imprescindível, na medida em que outras decisões anteriores já haviam previsto a possibilidade de controle das leis. SANTIAGO, Marcus Firmino. As origens do judicial review: porque Marbury vs. Madison é apenas um elo em uma longa cadeia. Revista da Ajuris, Porto Alegre, v. 44, n. 143, p. 331-355, dez. 2017, p. 333; ARAÚJO, Luiz Henrique Diniz. Constitutional Law around the globe: judicial review in the United States and the "writ of certiorari". Revista de Investigações Constitucionais, Curitiba, vol. 7, n. 1, p. 189-204, jan./abr. 2020. p. 192.

7 SANTIAGO, Marcus Firmino. As origens do judicial review: porque Marbury vs. Madison é apenas um elo em uma longa cadeia. Revista da Ajuris, Porto Alegre, v. 44, n. 143, p. 331-355, dez. 2017, p. 344-345; Ver também: CASAGRANDE, Cássio Luís; TIBÚRCIO, Dalton Robert. Marbury v. Madison: uma decisão política de manter a Corte fora da política. A\&C - Revista de Direito Administrativo \& Constitucional, Belo Horizonte, ano 19, n. 76, p. 199-224, abr./jun. 2019; SANTOS, Michele Carvalho; OLIVEIRA, Leandro Corrêa de. O mito de Marbury v. Madison: a questão da fundação da supremacia judicial. Revista de Investigações Constitucionais, Curitiba, vol. 5, n. 3, p. 325-347, set./dez. 2018.
}

8 CAPPELLETTI, Mauro. Juízes legisladores? Porto Alegre: Fabris, 1993, p. 43-44. 
Indo além, a partir do término da II Guerra Mundial passou a florescer o Estado Democrático de Direito, caracterizado pela defesa de direitos fundamentais e da dignidade da pessoa humana, modelo no qual a Constituição acaba por assumir uma função principiológica. Nesse momento histórico, o Poder Judiciário passa a desenvolver um papel de extrema importância, na medida em que surge, a partir dos episódios verificados no âmbito dos regimes totalitários, a insegurança em deixar a Constituição à mercê da vontade do legislador. Portanto, passa-se a defender a ideia de que caberia ao Judiciário (ou, no caso da Europa, aos Tribunais Constitucionais) o poder de decidir sobre questões constitucionais, que culmina, justamente, no papel do controle de constitucionalidade?.

Assim, ainda se poderia questionar: por que, com o Estado Democrático de Direito, o Poder Judiciário passa a ganhar espaço? Nesse modelo, os direitos fundamentais e a dignidade da pessoa humana assumem papel principal e, dessa forma, o Judiciário assume força como forma de proteção a esses valores e à própria Constituição, através, notadamente, do controle de constitucionalidade, não deixando a Lei Maior à mercê da discricionariedade do Poder Legislativo. O Estado Democrático de Direito desenvolve-se justamente no contexto pós II Guerra Mundial e, assim sendo, há grande preocupação por parte da sociedade que acabou de sair de um regime autoritário, violador de direitos, em ver esses direitos garantidos e concretizados ${ }^{10}$.

Diante desse quadro, essa função de averiguar se um texto legislativo está, ou não, em conformidade com o texto constitucional passa a pertencer à justiça constitucional, através, especificamente, da jurisdição constitucional, onde os Tribunais Constitucionais assumem um papel de destaque no cenário institucional. Lembra-se, ainda, que nessa conjuntura surgem grandes debates no que toca o controle de constitucionalidade, tendo especial relevância o debate entre Kelsen e Schmitt, ocorrido anos antes $^{11}$.

Referido debate teve início no fim da década de 1920, referente à Constituição de Weimar, e teve como centro determinar a quem melhor caberia a competência de zelar pela Constituição. Para Schmitt, a tarefa de proteger e guardar a Constituição

\footnotetext{
9 LEAL, Mônia Clarissa Hennig. Jurisdição constitucional aberta: reflexões sobre a legitimidade e os limites da jurisdição constitucional na ordem democrática. Rio de Janeiro: Lumen Juris, 2007, p. 40-41.

10 STRECK, Lênio Luiz. Jurisdição constitucional e hermenêutica: uma nova crítica do Direito. Porto Alegre: Livraria do Advogado, 2002, p. 98-100.

11 Vale lembrar que na época em que se desenrolou o debate entre Kelsen e Schmitt (década de 1920), não se falava em proteção de direitos fundamentais e da dignidade da pessoa humana. As Constituições nem mesmo previam esses direitos, e os Tribunais Constitucionais não detinham a função própria de protegê-los. Já no período pós II Guerra, os Tribunais Constitucionais que são instituídos nos países europeus avançam em relação à ideia cunhada inicialmente por Kelsen, incluindo-se, nesse momento, uma noção de guarda material da Constituição e de proteção dos direitos fundamentais, ideia essa que não se fazia presente no momento anterior. LEAL, Mônia Clarissa Hennig. Jurisdição constitucional aberta: reflexões sobre a legitimidade e os limites da jurisdição constitucional na ordem democrática. Rio de Janeiro: Lumen Juris, 2007, p. 40-41.
} 
deveria ser incumbida ao Führer do Reich alemão, pois o chefe do Executivo, eleito pelo povo e expressando a vontade da maioria, estaria mais qualificado para exercer tal papel, ao passo que os tribunais não teriam condições de manter a unidade do sistema jurídico e político. O principal argumento de Schmitt, ressalta-se, estava calcado na questão do aspecto político do controle de constitucionalidade. Para ele, ao conferir a função do controle de constitucionalidade aos magistrados estar-se-ia fazendo uma politização do judiciário, e não uma juridificação da política ${ }^{12}$.

Já para Kelsen quem deveria ser o guardião da Constituição e, portanto, o responsável pelo controle de constitucionalidade, seriam os Tribunais Constitucionais. Kelsen argumentou no sentido de que se por política entende-se "decisão", qualquer decisão e, portanto, qualquer sentença, detém um caráter político. Assim, não haveria o que se diferenciar, senão apenas quantitativamente, a aplicação de uma lei comum e o controle de constitucionalidade em $\mathrm{si}^{13}$.

Prevaleceu, por fim, a teoria kelseniana, embora não em sua plenitude. Vale ressaltar, ainda, que o sistema defendido por Kelsen, que adota a forma de controle concentrado, isto é - onde um único Tribunal (Tribunal Constitucional) é tido como competente para analisar e julgar as questões que envolvam a preservação da Constituição - não é o mesmo da judicial review americana, pois esta trata-se de controle difuso, segundo o qual não apenas um único Tribunal pode exercer tal tarefa, mas sim todo e qualquer juiz ${ }^{14}$.

Atenta-se ainda que, para Kelsen, o sistema legislativo divide-se em dois: no Parlamento (legislador positivo), de caráter político, e no Tribunal Constitucional (legislador negativo), existente para eliminar as leis que estão em desacordo com a Constituição. O nazismo, contudo, utilizou-se do Estado (formal) de Direito para legitimar as suas ações, momento em que a lei passou a ser utilizada como instrumento (e a legitimar) a prática de abusos e injustiças. Assim, esse fato levou ao engrandecimento dos Tribunais Constitucionais, tidos como instâncias capazes de proteger e concretizar direitos previstos na Constituição ${ }^{15}$, numa perspectiva contramajoritária.

Frisa-se, entretanto, que o modelo kelseniano transformou-se ao longo do tempo, haja vista que, a partir do segundo pós guerra, os Tribunais passaram a exercer uma jurisdição mais criativa, principalmente em razão da necessidade de se proteger e garantir os direitos fundamentais. A partir do fim da segunda guerra mundial, devido aos

\footnotetext{
12 SOUZA NETO, Cláudio Pereira de; SARMENTO, Daniel. Direito constitucional: teoria, história e métodos de trabalho. Belo Horizonte: Fórum, 2012, p. 22.

13 LEAL, Mônia Clarissa Hennig. Jurisdição constitucional aberta: reflexões sobre a legitimidade e os limites da jurisdição constitucional na ordem democrática. Rio de Janeiro: Lumen Juris, 2007, p. 45.

14 LEAL, Mônia Clarissa Hennig. Jurisdição constitucional aberta: reflexões sobre a legitimidade e os limites da jurisdição constitucional na ordem democrática. Rio de Janeiro: Lumen Juris, 2007, p. 46.

15 LEAL, Mônia Clarissa Hennig. Jurisdição constitucional aberta: reflexões sobre a legitimidade e os limites da jurisdição constitucional na ordem democrática. Rio de Janeiro: Lumen Juris, 2007, p. 46-47.
} 
horrores vivenciados em decorrência do nazismo e do fascismo, certos institutos acabaram se fortalecendo, como a noção de democracia, os direitos humanos, e a própria concepção de dignidade humana, aspectos que passaram a ocupar um lugar especial nas Constituições. Percebe-se que, com isso, a Constituição passa a proteger não apenas as maiorias, mas também aqueles que não detêm representatividade ou não possuem voz no jogo político, configurando um papel contramajoritário ${ }^{16}$. É nesse cenário, portanto, que se desenvolvem jurisdições constitucionais mais atuantes, principalmente nos países mais afetados pela guerra, como Alemanha, Itália e Espanha ${ }^{17}$.

Dessa forma, é possível dizer que a novidade centra-se na questão de que anteriormente as Constituições abarcavam apenas a noção de uma dimensão subjetiva no que tange aos direitos fundamentais. Já, por outro lado, com as modificações percebidas nos textos constitucionais, tem-se que a qualificação material dos direitos fundamentais acaba por contemplar todo o direito, configurando uma verdadeira ordem objetiva de valores. O que quer se dizer, pois, é que a partir desse momento toda a ordem jurídica deve voltar-se para as bases principiológicas da Constituição, os direitos nela contemplados passam a ter efeito sobre todas as esferas do direito ${ }^{18}$.

Diante desse contexto, a consequência que se verifica é a natureza aberta que as Constituições passam a possuir, isso na medida que se faz necessária a atuação mais ativa dos Tribunais para que os direitos de fato sejam efetivados e garantidos. Assim, os Tribunais passam a adotar uma atividade mais criativa e hermenêutica, tendo em vista que de modo contrário não seria possível prezar pela concretização dos direitos previstos nas Constituições. Isso se intensifica, alerta-se, quando esses direitos estão em conflito justamente com outros direitos previstos na Constituição, momento em que não se tem uma resposta determinada e pronta, momento em que o Tribunal precisa analisar o caso concreto, bem como as particularidades e argumentações que o acompanham ${ }^{19}$.

No Brasil, a Constituição Federal de 1988 prevê a possibilidade de um controle de constitucionalidade que pode ser exercido de duas formas: difusa, por todo e qualquer juiz quando diante de um caso concreto, e concentrada, somente pelo Supremo Tribunal Federal, quando o próprio pedido da ação é a análise da constitucionalidade ${ }^{20}$. Desse modo, o mais alto Tribunal do País atua, por vezes, como órgão comum do Poder Judiciário, como instância recursal, e por vezes como Corte Constitucional, incumbido

\footnotetext{
16 MARTOS, José A. Montilla. Minoria política e Tribunal Constitucional. Madrid: Trotta, 2002, p. 87.

17 LEAL, Mônia Clarissa Hennig. Jurisdição constitucional aberta: reflexões sobre a legitimidade e os limites da jurisdição constitucional na ordem democrática. Rio de Janeiro: Lumen Juris, 2007, p. 52.

18 LEAL, Mônia Clarissa Hennig. A Constituição como princípio: os limites da jurisdição constitucional brasileira. São Paulo: Manole, 2003, p. 24-25.

19 LEAL, Mônia Clarissa Hennig. Jurisdição constitucional aberta: reflexões sobre a legitimidade e os limites da jurisdição constitucional na ordem democrática. Rio de Janeiro: Lumen Juris, 2007, p. 53-54.

20 MORAES, Alexandre de. Direito constitucional. 6. ed. São Paulo: Atlas, 1999, p. 541-557.
} 
da tarefa de guarda da Constituição. Nesse contexto, um dos papeis que merece distinção é a função contramajoritária por ele exercida, que será melhor detalhada no próximo item.

\section{AS POLÍTICAS DE AÇÃO AFIRMATIVA E A ATUAÇÃO DO SUPRE- MO TRIBUNAL FEDERAL NA PROTEÇÃO DAS MINORIAS}

As ações afirmativas centram-se na ideia de uma política implementada com o fim de se alcançar a igualdade material de determinado grupo que se encontra em situação de desigualdade fática em razão de causas históricas, culturais, sociais, econômicas, etc. (como, por exemplo, mulheres, negros, pessoas com deficiência, entre outros), visando à erradicação ou redução da discriminação existente. São, assim, também chamadas de políticas de discriminação positiva, ou benigna, possuindo, tendencialmente, caráter temporário ${ }^{21}$.

Nesse sentido, muito embora alguns ainda utilizem a expressão "tratamento preferencial" como forma de conceituar as políticas públicas de ação afirmativa, esse termo não merece vingar, haja vista que essas políticas, em verdade, não consistem em dar preferência a determinado grupo, mas sim em buscar igualá-los com o restante da sociedade. Assim, coloca Rios 22: "de fato, as ações afirmativas, examinadas pelo o prisma do fenômeno da discriminação institucional e das respostas jurídicas às modalidades indiretas de discriminação, não são tratamentos preferenciais, mas medidas profiláticas diante da desvantagem experimentada por certos grupos, decorrentes do racismo e de outras formas correlatas de preconceito".

Ademais, a terminologia "ação afirmativa" surgiu para tratar das questões relativas ao preconceito racial, entretanto hoje contempla inúmeros grupos sociais discriminados, excluídos ou em posição de desvantagem em determinada sociedade, como é o caso de grupos étnicos, religiosos, raciais ou de gênero. A questão, embora já existente em outros países, ganhou destaque nos Estados Unidos, onde discutiu-se muito, e ainda se discute, a respeito, principalmente no que tange às cotas raciais, tendo-se em vista o forte movimento negro lá existente. Por esse motivo, inclusive, utilizam-se como base argumentos desenvolvidos no cenário norte-americano, por meio do direito comparado, tendo-se sempre o cuidado em perceber as diferentes realidades entre aquele cenário e o brasileiro ${ }^{23}$.

21 SANTOS, Erika Karine; BEZERRA, Valesca Caetano. Ação afirmativa: a prática da igualdade sob a perspectiva de Flávia Piovesan (Brasil) e Ronald Dworkin (EUA). Revista Fides, Natal, v. 1, n. 1, p. 71-86, fev./jul. 2010 , p. 74. 22 RIOS, Roger Raupp. Ações afirmativas no direito constitucional brasileiro: reflexões a partir de debate constitucional estadunidense. In: SARLET, Ingo Wolfgang. Jurisdição e direitos fundamentais. Porto Alegre: Livraria do Advogado, 2005, p. 284.

23 SANTOS, Erika Karine; BEZERRA, Valesca Caetano. Ação afirmativa: a prática da igualdade sob a perspectiva de Flávia Piovesan (Brasil) e Ronald Dworkin (EUA). Revista Fides, Natal, v. 1, n. 1, p. 71-86, fev./jul. 2010 , p. 73. 
Vale referir que o termo "affirmative actions" foi suscitado, pela primeira vez, em 1935, nos Estados Unidos, referente, notadamente, às relações de trabalho, ficando proibida a discriminação contra membros dos sindicatos, de forma que "o objetivo era fazer cessar a discriminação utilizando-se da ação afirmativa para recolocar as suas vítimas naquela posição que teriam alcançado se não houvessem sido discriminadas"24. Entretanto, a questão passa a ser mais debatida a partir dos anos 60, cenário em que se verificam grandes reivindicações, pelos norte-americanos, em busca da igualdade de oportunidade para todos. O movimento negro, nesse período, ganha destaque e se fortalece, o que vem a contribuir para o desenvolvimento da ideia de ações afirmativas, enquanto medidas positivas a serem adotadas pelo Estado como forma de compensar a discriminação sofrida por determinado grupo. No mesmo sentido, aponta Moehlec$\mathrm{ke}^{25}$ que

no período, começam a ser eliminadas as leis segregacionistas vigentes no país, e o movimento negro surge como uma das principais forças atuantes, com lideranças de projeção nacional, apoiado por liberais e progressistas brancos, unidos numa ampla defesa de direitos. É nesse contexto que se desenvolve a ideia de uma ação afirmativa, exigindo que o Estado, para além de garantir leis anti-segregacionistas, viesse também a assumir uma postura ativa para a melhoria das condições da população negra.

No que tange ao direito internacional, existem diversos dispositivos que se coadunam e vão ao encontro das políticas de ação afirmativa - Tratados, Convenções, Declarações, Pactos - os quais proíbem qualquer forma de discriminação, objetivam a concretização da igualdade material e preveem políticas de promoção da igualdade racial. É o caso, por exemplo, da Declaração Universal dos Direitos Humanos, da Convenção Americana sobre Direitos Humanos, e da Convenção sobre a Eliminação de Todas as Formas de Discriminação Racial. Todos esses instrumentos, vale lembrar, foram ratificados pelo Brasil e, portanto, possuem caráter obrigatório, devendo ser cumpridos internamente ${ }^{26}$.

Nesse contexto, é possível perceber que, no cenário internacional, há vontade em se ver prosperar o princípio da não-discriminação, o qual deve estar em harmonia com as ações afirmativas, haja vista essa articulação resultar, em última análise, em inclusão social. Assim, não basta não ser discriminado, é preciso que esse princípio seja complementado pela adoção de medidas que culminem na emancipação, autonomia

24 VILAS-BOAS, Renata Malta. Ações afirmativas e o princípio da igualdade. Rio de Janeiro: América Jurídica, 2003, p. 33.

25 MOEHLECKE, Sabrina. Ação afirmativa: história e debates no Brasil. Revista Cadernos de Pesquisa, n. 117, p. 197-217, nov. 2002, p. 198.

26 SILVA, Luiz Fernando Martins da. Considerações sobre o tema "políticas públicas de ação afirmativa para a população negra no Brasil". Revista Direito e Práxis, v. 3, n. 2, p. 122-153, 2011, p. 131. 
e independência de grupos ainda em situação de vulnerabilidade. Trindade ${ }^{27}$, nessa linha, sustenta que "o princípio da não-discriminação ocupa uma posição central no Direito Internacional dos Direitos Humanos. Encontra-se consagrado em diversos tratados e declarações de direitos humanos, e mesmo como elemento integrante do direito internacional consuetudinário".

No âmbito interno, é possível dizer que diversas previsões constitucionais e os princípios que orientam toda a ordem jurídica brasileira apontam para a constitucionalidade das ações afirmativas. ${ }^{28}$ Tem-se a previsão expressa, na Constituição Federal de 1988, da possibilidade de discriminação positiva, como por exemplo a proteção da muIher no mercado de trabalho, a reserva de vagas em cargos públicos para pessoas com deficiência, ${ }^{29}$ bem como a proteção da cultura indígena e afro-brasileira ${ }^{30}$. Além disso, leis ordinárias já foram editadas nesse sentido, como é o caso da Lei n 7.853/1989, Lei n 9.394/1996 e da Lei n 9.504/1997; e, no que se refere às cotas raciais, tem-se a Lei nº $12.990 / 2014$, referente às cotas para concursos da administração pública federal, a qual será objeto de análise mais detalhada no último item deste trabalho.

Indo além, quando se fala no tema das ações afirmativas, imperioso tratar da questão da igualdade material, que é justamente um dos fins a serem alcançados no âmbito do Estado Democrático de Direito. Superando a igualdade formal, ou jurídica, que se consubstancia na ideia de igualdade entre os indivíduos apenas num sentido teórico, situando todos num mesmo nível de proteção, a igualdade material trata-se, em verdade, de uma igualdade num sentido prático, real, que objetiva a nivelação dos indivíduos considerando a desigualdade presente entre eles ${ }^{31}$. Significa dizer, portanto, não tratar todos da mesma forma, pois, se assim o fosse, estar-se-ia perpetuando a desigualdade existente. Igualdade material é procurar igualar os indivíduos considerando

27 TRINDADE, Augusto Cançado. $\mathbf{O}$ direito internacional em um mundo em transformação. Rio de Janeiro: Renovar, 2002, p. 55.

28 DUARTE, Evandro Piza; BERTÚLIO, Dora Lucia de Lima; QUEIROZ, Marcos. Direito à liberdade e à igualdade nas políticas de reconhecimento: fundamentos jurídicos da identificação dos beneficiários nas cotas raciais. A\&C - Revista de Direito Administrativo \& Constitucional, Belo Horizonte, ano 20, n. 80, p. 173-210, abr./jun. 2020.

29 ARAÚJO, Luiz Alberto David; MAIA, Maurício. Inclusão e concurso público: análise crítica da jurisprudência sobre pessoas com deficiência. A\&C - Revista de Direito Administrativo \& Constitucional, Belo Horizonte, ano 16, n. 65, p. 135-157, jul./set. 2016.

30 BRASIL. Constituição (1988). Constituição da República Federativa do Brasil. Brasília, DF: Senado Federal, 1988. Disponível em: http://www.planalto.gov.br/ccivil_03/constituicao/constituicaocompilado.htm. Acesso em: 19 jul. 2019.

31 Alexy fala em um "paradoxo da igualdade", haja vista que para se alcançar a igualdade fática (material), é necessária a adoção de um tratamento diferenciado entre os indivíduos que se encontram em situação desigual, configurando, teoricamente, uma desigualdade jurídica. ALEXY, Robert. Teoria de los derechos fundamentales. Madrid: Centro de Estudios Constitucionales, 1999, p. 404. 
as diferenças, ou seja, é aplicar um tratamento diferenciado, justamente com o fim de se alcançar a paridade ${ }^{32}$.

Nesse sentido, indo ao encontro do princípio da igualdade material, "as ações afirmativas objetivam, de um ponto de vista fático, novas condições de vida, mediante a transformação da realidade existente; dito de outro modo, elas reclamam a criação da igualdade fática"33. Feres Júnior ${ }^{34}$, de forma complementar, assevera que "deve-se ter claro que a ação afirmativa visa atacar especificamente a reprodução da desigualdade que escapa o alcance das políticas universais". Assim, as políticas de ações afirmativas são, em verdade, medidas admissíveis, quando se tem como objetivo alcançar o princípio da igualdade material, sendo, portanto, constitucionalmente válidas.

Diante de tal conjuntura, é preciso, antes de tudo, reconhecer a existência do racismo estrutural presente na sociedade brasileira e da discriminação racial que se perpetuou no tempo e ainda permanece viva. Após esse reconhecimento, é necessário combater o problema, momento em que surge a possibilidade de implementação de políticas de ações afirmativas, medidas temporárias com o objetivo de alcançar a igualdade e equilibrar as oportunidades. Flávia Piovesan ${ }^{35}$ caminha no mesmo sentido, ao colocar que: "a implementação do direito à igualdade racial há de ser um imperativo ético-político-social, capaz de enfrentar o legado discriminatório que tem negado à metade da população brasileira o pleno exercício de seus direitos e liberdades fundamentais".

Na mesma linha, Dworkin ${ }^{36}$ esclarece que os cargos de prestígio e os altos postos da sociedade sempre estiveram e ainda permanecem na posse de uma maioria branca. Não se pode dizer, portanto, que há igualdade entre as raças, motivo pelo qual o autor incentiva a adoção de políticas de ação afirmativa, caso contrário estar-se-ia simplesmente ignorando o problema (que se sabe que é real) e mantendo a estratificação racial. Além disso, o autor faz alusão às estatísticas que confirmam essa análise e complementa que seria um erro proibir a adoção dessas medidas.

Dito isso, importante clarear alguns aspectos quanto ao papel contramajoritário desenvolvido pelo Supremo Tribunal Federal. É preciso reconhecer, inicialmente, a existência de uma relação multifacetada entre os conceitos de Estado de Direito e

\footnotetext{
32 SIQUEIRA, Dirceu Pereira; ROSTELATO, Telma Aparecida. Inclusão social, processo coletivo e minorias no ordenamento jurídico brasileiro. Revista USCS, ano X, n. 16, p. 221-237, jan./jun. 2009. Disponível em: http:// seer.uscs.edu.br/index.php/revista_direito/article/viewFile/878/731. Acesso em: 06 jul. 2019, p. 227-228.

33 RIOS, Roger Raupp. Ações afirmativas no direito constitucional brasileiro: reflexões a partir de debate constitucional estadunidense. In: SARLET, Ingo Wolfgang. Jurisdição e direitos fundamentais. Porto Alegre: Livraria do Advogado, 2005, p. 295.

34 FERES JÚNIOR, João. Ação afirmativa no Brasil: fundamentos e críticas. Revista Econômica, Rio de Janeiro, v. 6, n. 2, p. 291-312, dez. 2004, p. 303.

35 PIOVESAN, Flávia. Direitos humanos e o direito constitucional internacional. São Paulo: Max Limonad, 2005, p. 43.

36 DWORKIN, Ronald. A virtude soberana: a teoria e a prática da igualdade. São Paulo: Martins Fontes, 2005, p. 579.
} 
Democracia, os quais, por vezes, conflitam entre si. O primeiro está intimamente conectado com os próprios direitos fundamentais, previstos em uma Constituição rígida, ao passo que o segundo relaciona-se com a ideia de maioria, pois conecta-se com a noção de um poder eleito democraticamente, isto é, eleito pela maioria. Desse modo, Dworkin desenvolve uma ideia capaz de ilustrar essa questão, ao colocar que os direitos fundamentais podem ser concebidos como "trunfos" contra o Estado, contra a maioria ${ }^{37}$.

Nesse contexto, ao mesmo tempo em que os dois conceitos são indissociáveis, haja vista que para que haja Estado de Direito é necessário haver Democracia e para que haja Democracia é preciso haver respeito aos direitos fundamentais, também existe uma constante tensão entre eles, havendo momentos em que um prevalecerá sobre o outro. Assim, "essa tensão verifica-se porque a maioria no poder (mesmo pressupondo que tal poder teve origem e legitimação democráticas) pode ameaçar os direitos fundamentais" ${ }^{\prime 38}$. Entretanto, os direitos fundamentais também podem inibir o exercício da democracia, a partir do momento em que tem-se um Poder Judiciário, não eleito democraticamente, apto a intervir e agir em defesa dos direitos fundamentais, contrariando, inclusive, o legislador, quando for o caso. E complementa o autor que "não raras vezes acontecerá, então, que a minoria derrotada no Parlamento venha, a posteriori, a obter no Tribunal Constitucional, ou no órgão judicial responsável pela jurisdição constitucional, vencimento sobre a maioria democraticamente eleita, o que, obviamente, constitui a mais directa (sic) contestação institucional ao princípio da maioria"39.

Diante de tal conjuntura, é possível dizer que os direitos fundamentais em si, assim como uma Constituição rígida, e principalmente a jurisdição constitucional (no Brasil representada pelo Supremo Tribunal Federal), possuem uma vertente contramajoritária, pois impõem limites à atuação do legislador, isto é, limitam a margem de atuação do legislador, eleito pela maioria, democraticamente. Dito de outro modo, a jurisdição constitucional tem a prerrogativa de invalidar, condicionar ou dar um sentido diverso às medidas legislativas e executivas, em nome da proteção dos direitos fundamentais. Com isso, é possível que a vontade da maioria, expressada por meio dos Poderes Legislativo e Executivo, nem sempre prospere, que é justamente o momento em que, no caso do Brasil, o Supremo Tribunal Federal age na defesa dos direitos fundamentais das minorias, por vezes sem representatividade e consequentemente esquecidas pelos poderes políticos ${ }^{40}$.

Assim, a partir do que foi trabalhado até o presente momento, procurar-se-á analisar a decisão proferida no ano de 2017 pelo Supremo Tribunal Federal, em sede de controle abstrato de constitucionalidade, ação esta que julga a constitucionalidade das

37 DWORKIN, Ronald. Levando os direitos a sério. 1. ed. São Paulo: Martins Fontes, 2002.

38 NOVAIS, Jorge Reis. Direitos fundamentais: trunfos contra a maioria. Coimbra: Coimbra, 2006, p. 21.

39 NOVAIS, Jorge Reis. Direitos fundamentais: trunfos contra a maioria. Coimbra: Coimbra, 2006, p. 22.

40 NOVAIS, Jorge Reis. Direitos fundamentais: trunfos contra a maioria. Coimbra: Coimbra, 2006, p. 21-23. 
cotas raciais para concursos públicos da administração pública federal: Ação Declaratória de Constitucionalidade $n^{\circ} 41$, por meio da qual pretender-se-á verificar os principais argumentos abordados pelos Ministros, a forma como se deu essa argumentação e o exercício do papel contramajoritário confiado ao Tribunal na proteção de direitos de uma minoria específica.

\section{RESERVA DE VAGAS PARA NEGROS EM CONCURSOS PÚBLICOS COMO ESTRATÉGIA DE INCLUSÃO SOCIAL E DE PROTEÇÃO DE MINORIAS: ANÁLISE CRÍTICA DA ADC 41}

A Ação Declaratória de Constitucionalidade no 41 (ADC 41) foi julgada no dia 08 de junho de 2017 pelo Supremo Tribunal Federal. Trata-se de ação interposta pelo Conselho Federal da Ordem dos Advogados do Brasil (OAB) com o objetivo de obter a declaração de constitucionalidade da Lei no 12.990/2014, a qual estabelece o percentual de $20 \%$ de cotas para negros em concursos públicos da administração pública federal. ${ }^{41} \mathrm{O}$ autor da demanda sustenta a necessidade da declaração da constitucionalidade pelo Tribunal em razão da existência de controvérsia judicial relevante quanto ao tema, o que causa insegurança jurídica. Ademais, ressalta-se, de início, que dois foram os principais tópicos analisados ao longo da decisão, quais sejam, a constitucionalidade em si das cotas raciais, bem como a constitucionalidade do critério de identificação dos candidatos: autodeclaração e heteroidentificação ${ }^{42}$.

No que tange aos requisitos para a interposição de uma ação de controle de constitucionalidade concentrado, especificamente, de uma ação declaratória de constitucionalidade ${ }^{43}$ destaca-se que todos foram cumpridos ${ }^{44}$. A competência para julgamento da demanda é exclusiva do Supremo Tribunal Federal (o qual, nesse cenário, exerce a função de um "Tribunal Constitucional"); a legitimidade ativa foi exercida por órgão competente, previsto na Constituição Federal de 1988, qual seja, o Conselho

41 Há quem defenda haver sub-representação legal no percentual estabelecido pela lei. Nesse sentido: DUARTE; Evandro Piza; FERREIRA, Gianmarco Loures. Sub-representação legal nas ações afirmativas: a Lei de Cotas nos concursos públicos. A\&C - Revista de Direito Administrativo \& Constitucional, Belo Horizonte, ano 17, n. 70, p. 199-235, out./dez. 2017.

42 BRASIL. Supremo Tribunal Federal. Ação Declaratória de Constitucionalidade n 41/Distrito Federal. Disponível em: http://redir.stf.jus.br/paginadorpub/paginador.jsp?docTP=TP\&docID=13375729. Acesso em: 4 jun. 2019.

43 Sobre a polêmica em torno da figura da Ação Declaratória de Constitucionalidade, ver o debate entre: MAGALHÃES, Breno Baía. Quem tem medo da ADC? Os 20 anos da Ação Declaratória de Constitucionalidade e a judicialização da política no STF. A\&C - Revista de Direito Administrativo \& Constitucional, Belo Horizonte, ano 17, n. 67, p. 217-261, jan./mar. 2017, e LAURENTIIS, Lucas Catib De. Tenho medo, do medo, do medo da ADC: uma resposta a Breno Magalhães. A\&C - Revista de Direito Administrativo \& Constitucional, Belo Horizonte, ano 18, n. 73, p. 141-162, jul./set. 2018.

44 BRASIL. Supremo Tribunal Federal. Ação Declaratória de Constitucionalidade $\mathbf{n}^{\circ}$ 41/Distrito Federal. Disponível em: http://redir.stf.jus.br/paginadorpub/paginador.jsp?docTP=TP\&docID=13375729. Acesso em: 4 jun. 2019. 
Federal da Ordem dos Advogados do Brasil (OAB) - legitimado universal45; foi exercida contra lei federal (Lei no 12.990/2014), promulgada após a Constituição Federal de 1988; bem como atendeu-se a exigência de controvérsia judicial relevante ${ }^{46}$, ficando comprovada, na ação, a existência de julgamentos que contrariam a lei em questão, considerando-a inconstitucional ${ }^{47}$.

Em relação às decisões que afastaram a aplicabilidade da referida Lei, em sede de controle difuso de constitucionalidade, sobressaem argumentos que afirmam que a política de ação afirmativa de cotas raciais (objeto da Lei n 12.990/2014) ofende os princípios constitucionais da igualdade, da proporcionalidade, do concurso público e da eficiência, argumentos que foram todos afastados pelos Ministros do Supremo Tribunal Federal, por unanimidade, na $\operatorname{ADC~} 41^{48}$, conforme se verá.

Frisa-se que os fundamentos explanados pelos Ministros correlacionam-se, caminham num mesmo sentido e estão em plena harmonia, motivo pelo qual, inclusive, não houve divergências significativas ao longo da sentença. Primeiramente há que se falar da questão do racismo estrutural presente na sociedade brasileira, que, como coloca o Ministro Luís Roberto Barroso, é um racismo silencioso, velado, encoberto. Trata-se da existência de uma discriminação racial, bem como de diferenças significativas entre brancos e negros quando se fala em níveis de escolaridade, postos de poder, nível salarial, cargos de trabalho (inclusive no setor público), e espaços elitizados. Dessa forma, questiona-se: como falar em mérito se apenas se olha para a linha de chegada, mas não para o ponto de partida? ${ }^{49}$.

45 Quanto aos legitimados ativos para a interposição de ações de controle de constitucionalidade concentrado (ADI, $A D I(O), A D C$ e ADPF), refere-se que se subdividem em duas categorias: legitimados universais e legitimados especiais. Os segundos, conforme previsão constitucional, e em lei específica (Lei n 9868/1999), precisam apresentar um requisito especial: a existência de pertinência temática, isto é, a comprovação da relação da pretensão judicial com os seus objetivos institucionais, e os primeiros, por outro lado, não necessitam comprovar esse requisito. BRASIL. Lei no 9.868 (1999). Brasília, DF: Senado Federal, 1999. Disponível em: http://www.planalto.gov.br/ccivil_03/leis/L9868.htm. Acesso em: 26 jul. 2019.

46 Quanto a esse aspecto, importante ter claro o porquê da necessidade da existência de controvérsia judicial relevante para a interposição dessa ação específica (ADC). Veja-se, todas as leis e atos normativos possuem presunção de constitucionalidade, haja vista serem produto de órgãos legitimados (Poderes Legislativo ou Executivo). Assim, todas as leis e demais atos normativos, quando nascem, presumem-se estarem em consonância com a Constituição Federal, motivo pelo qual somente em razão da existência de controvérsia judicial em relação à constitucionalidade de determinada lei, pode-se requerer que o Supremo Tribunal Federal interfira e declare que essa lei é, de fato, constitucional, conforme se presumia. BARROSO, Luís Roberto. Interpretação e aplicação da Constituição. São Paulo: Saraiva, 1998, p. 164-165.

47 BRASIL. Constituição (1988). Constituição da República Federativa do Brasil. Brasília, DF: Senado Federal, 1988. Disponível em: http://www.planalto.gov.br/ccivil_03/constituicao/constituicaocompilado.htm. Acesso em: 19 jul. 2019.

48 BRASIL. Supremo Tribunal Federal. Ação Declaratória de Constitucionalidade n 41/Distrito Federal. Disponível em: http://redir.stf.jus.br/paginadorpub/paginador.jsp?docTP=TP\&docID=13375729. Acesso em: 4 jun. 2019.

49 BRASIL. Supremo Tribunal Federal. Ação Declaratória de Constitucionalidade n 41/Distrito Federal. Disponível em: http://redir.stf.jus.br/paginadorpub/paginador.jsp?docTP=TP\&docID=13375729. Acesso em: 4 jun. 2019. 
O que se quer dizer, pois, é que o racismo ainda hoje existente é produto, também, da escravidão passada e da sua abolição sem que houvesse qualquer planejamento ou política de integração do ex-escravo na sociedade. Assim, impossível pensar que com essa origem, e sem nenhum apoio institucional, essas pessoas possuam as mesmas oportunidades, mesmas chances e mesma possibilidade de concorrência que os demais:

no tocante à reparação histórica, nem há muita necessidade de se investir energia. Ela decorre da escravidão e de pessoas que foram retiradas, à força, do seu habitat natural e depois submetidas a trabalhos forçados e a condições degradantes de vida. E quando vem a abolição do regime escravocrata, essas pessoas são liberadas na sociedade sem nenhum planejamento, sem nenhuma integração, sem nenhum tipo de preparação para viver como pessoas livres em uma sociedade - liberal seria exagero - que começava a se liberalizar. Portanto, e não sem surpresa, como lembrado também da tribuna, na passagem de Joaquim Nabuco, mesmo depois de libertados, os negros continuaram a desempenhar as funções mais subalternas dentro de uma sociedade altamente hierarquizada como a nossa $a^{50}$.

Dessa forma, toda essa questão histórica influenciou e continua repercutindo efeitos na sociedade atual, o que pode ser comprovado pelas estatísticas e pesquisas que demonstram e ilustram a desigualdade presente. Em razão disso, portanto, não se pode afirmar que há igualdade de condições entre negros e brancos no momento em que esses competem entre si (tanto no acesso à vagas em universidades, quanto no acesso a cargos públicos), veja-se:

no caso dos candidatos negros, parece evidente que inúmeros fatores, como a ausência de condições financeiras para aquisição de material didático, para frequentar cursos preparatórios e para dedicar-se exclusivamente ao estudo, os impedem de competir em pé de igualdade com os demais concorrentes, razão pela qual se exige do Estado uma atuação positiva no sentido de calibrar os critérios para aferir o mérito dos candidatos ${ }^{51}$.

Nessa linha, no que se refere à igualdade, foi pacífica a noção de que esse princípio aberto possui três facetas, sendo elas a igualdade formal, a material e a igualdade como reconhecimento, e em nenhum ponto a Lei violaria esse direito constitucional, muito pelo contrário, estaria o garantindo, na medida em que promove a equiparação

50 BRASIL. Supremo Tribunal Federal. Ação Declaratória de Constitucionalidade n 41/Distrito Federal. Disponível em: http://redir.stf.jus.br/paginadorpub/paginador.jsp?docTP=TP\&docID=13375729. Acesso em: 4 jun. 2019.

51 BRASIL. Supremo Tribunal Federal. Ação Declaratória de Constitucionalidade $\mathbf{n}^{\circ}$ 41/Distrito Federal. Disponível em: http://redir.stf.jus.br/paginadorpub/paginador.jsp?docTP=TP\&docID=13375729. Acesso em: 4 jun. 2019. 
entre negros (minoria estigmatizada) e a sociedade brasileira. No que toca o argumento de que haveria violação ao concurso público, tem-se que os negros que concorrem às vagas precisam, obrigatoriamente, alcançar o número mínimo de acertos, precisam prestar o concurso público e cumprir com todos os requisitos exigidos, da mesma forma que os demais candidatos, motivo pelo qual não há como prosperar essa justificativa ${ }^{52}$.

Quanto à "suposta" violação ao princípio da eficiência ${ }^{53}$, tem-se que não necessariamente os melhores colocados são, de fato, mais eficientes, além de que a questão da eficiência ultrapassa o aspecto da pontuação realizada no concurso, alcançando, por exemplo, a ideia de diversidade e pluralidade, qualidades que se sobressairão quando se verificar maior representatividade de negros e pardos na ocupação de cargos públicos. Já no que se refere ao princípio da proporcionalidade, que alega-se ser violado por já existirem cotas raciais para o acesso de vagas nas universidades, tem-se que não necessariamente o acesso à educação repercutirá (de forma imediata) na competitividade no mercado de trabalho: essa conexão demanda tempo, não se desenvolve automaticamente. Além disso, não se pode afirmar que são as mesmas pessoas que utilizarão a política de cotas no acesso à universidade e as cotas para concursos públicos. Por fim, ainda no que tange esse último argumento (proporcionalidade), tem-se que os cargos públicos disputados nem sempre serão relativos ao nível superior, assim, por todos os motivos explanados, conclui-se que não há violação do princípio ${ }^{54}$.

Foi destacado, também, o alto grau de legitimidade democrática que ampara a Lei questionada, haja vista ter sido aprovada pela unanimidade de senadores e quase totalidade de deputados federais, o que acarreta a necessidade de uma robusta argumentação para que seja possível julgar pela inconstitucionalidade da lei, argumentação essa que se mostrou insuficiente, pois toda a lógica constitucional, e inclusive internacional, apontam para a validade da Lei questionada. Ademais, ao longo da decisão muito se fez referência à ADPF no 186, ação que julgou a constitucionalidade da política de ação afirmativa - cotas raciais - para ingresso na Universidade de Brasília (UnB). ${ }^{55} \mathrm{As}-$ sim, de forma comparativa, os contrários às cotas para negros para concursos públicos

52 BRASIL. Supremo Tribunal Federal. Ação Declaratória de Constitucionalidade n 41/Distrito Federal. Disponível em: http://redir.stf.jus.br/paginadorpub/paginador.jsp?docTP=TP\&docID=13375729. Acesso em: 4 jun. 2019.

53 Nesse ponto a decisão ainda abarcou a questão da meritocracia, trazendo que não se pode comparar indivíduos que tem uma diferença abismal no ponto de partida e apenas analisar o resultado final, sem considerar as diferenças e desigualdade de condições existentes. BRASIL. Supremo Tribunal Federal. Ação Declaratória de Constitucionalidade n 41/Distrito Federal. Disponível em: http://redir.stf.jus.br/paginadorpub/paginador.jsp?docTP=TP\&docID=13375729. Acesso em: 4 jun. 2019.

54 BRASIL. Supremo Tribunal Federal. Ação Declaratória de Constitucionalidade n 41/Distrito Federal. Disponível em: http://redir.stf.jus.br/paginadorpub/paginador.jsp?docTP=TP\&docID=13375729. Acesso em: 4 jun. 2019.

55 Ver: BUCCl, Maria Paula Dallari. As ações afirmativas no Supremo Tribunal Federal: conexões entre direito e política na difícil promoção da equidade racial no Brasil. A\&C - Revista de Direito Administrativo \& Constitucional, Belo Horizonte, ano 21, n. 83, p. 51-74, jan./mar. 2021. 
alegam que, diferentemente do caso da ADPF n 186, no caso em tela não trata-se de proteção ao direito fundamental à educação, mas sim de acesso a cargo público, que não é um direito fundamental e, portanto, não justificaria a adoção de uma política de cotas. Além desse argumento, justificou-se que opera-se o bis in idem, na medida em que negros e pardos poderiam ser beneficiados ${ }^{56}$ duplamente: primeiro no ingresso na universidade, segundo no acesso a cargos públicos, justificativas que não foram acatadas pelos Ministros pelos motivos já abordados acima ${ }^{57}$.

Indo adiante, outro ponto muito debatido ao longo da sentença centra-se na questão de como identificar se um candidato é, ou não, contemplado pela política de cotas. Debateu-se se deveria prevalecer o critério da autodeclaração ou da heteroidentificação, prevalecendo a tese de que, como regra, deve-se utilizar o primeiro critério, por preservar a noção de como o próprio indivíduo se percebe e se identifica ${ }^{58}$, e somente de forma subsidiária, com o fim de evitar-se fraudes, permitir-se-á a utilização do segundo critério, que poderá se dar através de provas documentais, fotos e entrevistas, por exemplo, desde que respeitada a dignidade da pessoa humana do candidato, bem com garantidos o contraditório e a ampla defesa, mantendo-se, dessa forma, o texto da Lei ${ }^{59}$.

Diante do que foi exposto, pode-se dizer que os argumentos apresentados pelos Ministros do Supremo Tribunal Federal se deram de forma coerente, técnica e didática, percebendo-se uma construção detalhada e técnica acerca de vários conceitos abertos previstos na Constituição Federal de 1988, como é o caso do princípio da igualdade, bem como da refutação específica de cada justificativa contrária à adoção da política de cotas raciais. Ademais, fez-se menção a diversos dispositivos internacionais, como a Convenção Internacional sobre a Eliminação de Todas as Formas de Discriminação Racial e a Declaração Universal dos Direitos da Pessoa Humana, que se coadunam com a lógica das políticas de ação afirmativa, demonstrando a importância em se cumprir, também, com a ordem internacional.

\footnotetext{
56 Percebe-se, aqui, o uso da terminologia "beneficiados", o que não considera-se adequado, tendo em vista que as políticas de ações afirmativas, como visto anteriormente, não tratam-se de privilégios, benefícios, mas sim de uma medida reparadora, que visa igualar condições.

57 BRASIL. Supremo Tribunal Federal. Ação Declaratória de Constitucionalidade n 41/Distrito Federal. Disponível em: http://redir.stf.jus.br/paginadorpub/paginador.jsp?docTP=TP\&docID=13375729. Acesso em: 4 jun. 2019.

58 Na decisão, de forma comparativa, lembrou-se da questão dos transgêneros e do acesso aos banheiros públicos: o indivíduo é visto como homem, mas se sente e se autopercebe como mulher, ou o contrário, e determinar algo diferente acabaria ferindo a sua dignidade, motivo pelo qual há que ser respeitada a maneira como as pessoas se identificam (BRASIL, 2017, www.stf.jus.br).

59 BRASIL. Supremo Tribunal Federal. Ação Declaratória de Constitucionalidade $\mathbf{n}^{\circ}$ 41/Distrito Federal. Disponível em: http://redir.stf.jus.br/paginadorpub/paginador.jsp?docTP=TP\&docID=13375729. Acesso em: 4 jun. 2019.
} 
Por fim, no que tange ao papel do Supremo Tribunal Federal na proteção das minorias, conclui-se que, nessa decisão específica, foi cumprido com eficiência, haja vista que o caso trata-se da preservação de direitos de uma minoria histórica e estigmatizada, que são os negros, e o Tribunal se manifestou a seu favor e a favor da Constituição. Tratou-se da questão da igualdade (principalmente a material e de reconhecimento) e assumiu-se um problema que muitas vezes é negado no Brasil: existe hoje ainda preconceito e discriminação racial e, não bastasse isso, ainda percebem-se as consequências de um desenrolar histórico, que se consubstancia no desequilíbrio e na desigualdade de condições e concorrência entre brancos e negros, o que torna constitucional a utilização das cotas raciais.

\section{CONCLUSÃO}

Inicialmente tratou-se da origem e da evolução do mecanismo intitulado controle de constitucionalidade, verificando-se a existência de dois modelos, o difuso, oriundo do direito norte-americano, a partir do caso Marbury v. Madison, e o concentrado, de inspiração continental europeia, proveniente do debate travado entre Kelsen e Schmitt. E, embora assim não tenha sido na sua origem, atualmente trata-se de um mecanismo que tem como objetivo a garantia de proteção da Constituição e dos direitos fundamentais por ela tutelados, motivo pelo qual a jurisdição constitucional e o controle de constitucionalidade se fortaleceram a partir da ascensão do Estado Democrático de Direito e do reconhecimento de uma ordem objetiva de valores.

Através do controle de constitucionalidade percebe-se, também, a possibilidade da proteção dos direitos das minorias, esquecidas, muitas vezes, pelos poderes políticos eleitos, momento em que se visualiza o papel contramajoritário exercido pelo Supremo Tribunal Federal. As políticas de ação afirmativa, que nascem no intuito de ser ver garantido o princípio da igualdade material, assegurado tanto pela ordem jurídica internacional, quanto pela Constituição Federal de 1988, são, não raras vezes, questionadas pela sociedade, como se verificou no caso da Ação Declaratória de Constitucionalidade n 41 (ADC 41), ajuizada em razão da controvérsia judicial quanto à constitucionalidade da política de ação afirmativa referente às vagas reservadas para negros em concursos públicos da administração pública federal.

Por meio da análise dessa ação de controle de constitucionalidade concentrado, verificou-se os argumentos utilizados pelos Ministros, os quais se coadunam e vão ao encontro da ordem jurídica vigente, tanto no que toca o âmbito externo, como o interno, conforme já referido. Defendeu-se a constitucionalidade e a aplicabilidade da Lei de cotas para negros em concursos públicos da administração pública federal, frisando-se a necessidade do reconhecimento da disparidade existente entre negros e brancos no Brasil, e do racismo estruturante ainda presente, motivos que, juntamente 
com comprovações estatísticas, demonstram a necessidade da implementação e do cumprimento de políticas que visem a concretização da igualdade material, isto é, de políticas que caminhem no sentido de diminuir e eliminar a desigualdade existente no quesito racial, no Brasil.

Com isso, pode-se responder a problemática suscitada no início do presente artigo, qual seja: como se dá a atuação do Supremo Tribunal Federal no que tange à proteção das minorias, com base na decisão proferida na ADC n 41 ? Verifica-se, nesse sentido, o desenvolvimento de uma postura ativa e em harmonia com os princípios abarcados pela Constituição Federal de 1988 e pelas Declarações e Tratados internacionais ratificados pelo Brasil, na medida em que aduziu argumentos no sentido de proteção das minorias, notadamente dos negros, bem como do reconhecimento da necessidade de se implementar, de fato, a igualdade material que se espera ver concretizada. Nesse sentido, o conceito de minorias adotado pelo STF na decisão analisada não se relaciona com a questão numérica, mas sim com o reconhecimento de um grupo de pessoas estigmatizado histórica e socialmente e que é vítima de uma discriminação estrutural, merecendo, portanto, ser objeto de proteção por políticas públicas de inclusão social e não-discriminação.

\section{REFERÊNCIAS}

ALEXY, Robert. Teoria de los derechos fundamentales. Madrid: Centro de Estudios Constitucionales, 1999.

ARAÚJO, Luiz Alberto David; MAIA, Maurício. Inclusão e concurso público: análise crítica da jurisprudência sobre pessoas com deficiência. A\&C - Revista de Direito Administrativo \& Constitucional, Belo Horizonte, ano 16, n. 65, p. 135-157, jul./set. 2016.

ARAÚJO, Luiz Henrique Diniz. Constitutional Law around the globe: judicial review in the United States and the "writ of certiorari". Revista de Investigações Constitucionais, Curitiba, vol. 7, n. 1, p. 189-204, jan./abr. 2020.

ARAÚJO, Luiz Henrique Diniz. Filtros de acesso às Cortes Constitucionais: a Questão Prioritária de Constitucionalidade e os filtros de acesso ao Conselho Constitucional Francês. Revista de Investigações Constitucionais, Curitiba, vol. 6, n. 2, p. 405-422, maio/ago. 2019.

BARROSO, Luís Roberto. Interpretação e aplicação da Constituição. São Paulo: Saraiva, 1998.

BRASIL. Constituição (1988). Constituição da República Federativa do Brasil. Brasília, DF: Senado Federal, 1988. Disponível em: http://www.planalto.gov.br/ccivil_03/constituicao/constituicaocompilado.htm. Acesso em: 19 jul. 2019.

BRASIL. Lei no 9.868 (1999). Brasília, DF: Senado Federal, 1999. Disponível em: http://www.planalto.gov.br/ccivil_03/leis/L9868.htm. Acesso em: 26 jul. 2019. 
BRASIL. Supremo Tribunal Federal. Ação Declaratória de Constitucionalidade n 41/Distrito Federal. Disponível em: http://redir.stf.jus.br/paginadorpub/paginador.jsp?docTP=TP\&doCID=13375729. Acesso em: 4 jun. 2019.

BUCCl, Maria Paula Dallari. As ações afirmativas no Supremo Tribunal Federal: conexões entre direito e política na difícil promoção da equidade racial no Brasil. A\&C - Revista de Direito Administrativo \& Constitucional, Belo Horizonte, ano 21, n. 83, p. 51-74, jan./mar. 2021.

CAPPELLETTI, Mauro. Juízes legisladores? Porto Alegre: Fabris, 1993.

CAPPELLETTI, Mauro. $\mathbf{O}$ controle judicial de constitucionalidade das leis no direito comparado. 2. ed. Porto Alegre: Sergio Antonio Fabris Editor, 1992.

CASAGRANDE, Cássio Luís; TIBÚRCIO, Dalton Robert. Marbury v. Madison: uma decisão política de manter a Corte fora da política. A\&C - Revista de Direito Administrativo \& Constitucional, Belo Horizonte, ano 19, n. 76, p. 199-224, abr./jun. 2019.

DUARTE, Evandro Piza; BERTÚLIO, Dora Lucia de Lima; QUEIROZ, Marcos. Direito à liberdade e à igualdade nas políticas de reconhecimento: fundamentos jurídicos da identificação dos beneficiários nas cotas raciais. A\&C - Revista de Direito Administrativo \& Constitucional, Belo Horizonte, ano 20, n. 80, p. 173-210, abr./jun. 2020.

DUARTE; Evandro Piza; FERREIRA, Gianmarco Loures. Sub-representação legal nas ações afirmativas: a Lei de Cotas nos concursos públicos. A\&C - Revista de Direito Administrativo \& Constitucional, Belo Horizonte, ano 17, n. 70, p. 199-235, out./dez. 2017.

DWORKIN, Ronald. A virtude soberana: a teoria e a prática da igualdade. São Paulo: Martins Fontes, 2005.

DWORKIN, Ronald. Levando os direitos a sério. 1. ed. São Paulo: Martins Fontes, 2002.

FACCHINI NETO, Eugênio; HENDGES, Carla Evelise Justino. E a França piscou: a questão prioritária de constitucionalidade e o fim do controle exclusivamente prévio de constitucionalidade. A\&C Revista de Direito Administrativo \& Constitucional, Belo Horizonte, ano 17, n. 67, p. 153-183, jan./mar. 2017.

FERES JÚNIOR, João. Ação afirmativa no Brasil: fundamentos e críticas. Revista Econômica, Rio de Janeiro, v. 6, n. 2, p. 291-312, dez. 2004.

LAURENTIIS, Lucas Catib De. Tenho medo, do medo, do medo da ADC: uma resposta a Breno Magalhães. A\&C - Revista de Direito Administrativo \& Constitucional, Belo Horizonte, ano 18, n. 73, p. 141-162, jul./set. 2018.

LEAL, Mônia Clarissa Hennig. Jurisdição constitucional aberta: reflexões sobre a legitimidade e os limites da jurisdição constitucional na ordem democrática. Rio de Janeiro: Lumen Juris, 2007.

LEAL, Mônia Clarissa Hennig. A Constituição como princípio: os limites da jurisdição constitucional brasileira. São Paulo: Manole, 2003. 
MAGALHÃES, Breno Baía. Quem tem medo da ADC? Os 20 anos da Ação Declaratória de Constitucionalidade e a judicialização da política no STF. A\&C - Revista de Direito Administrativo \& Constitucional, Belo Horizonte, ano 17, n. 67, p. 217-261, jan./mar. 2017.

MARTOS, José A. Montilla. Minoria política e Tribunal Constitucional. Madrid: Trotta, 2002.

MOEHLECKE, Sabrina. Ação afirmativa: história e debates no Brasil. Revista Cadernos de Pesquisa, n. 117, p. 197-217, nov. 2002.

MORAES, Alexandre de. Direito constitucional. 6. ed. São Paulo: Atlas, 1999.

NOVAIS, Jorge Reis. Direitos fundamentais: trunfos contra a maioria. Coimbra: Coimbra, 2006.

PIOVESAN, Flávia. Direitos humanos e o direito constitucional internacional. São Paulo: Max Limonad, 2005.

RIOS, Roger Raupp. Ações afirmativas no direito constitucional brasileiro: reflexões a partir de debate constitucional estadunidense. In: SARLET, Ingo Wolfgang. Jurisdição e direitos fundamentais. Porto Alegre: Livraria do Advogado, 2005.

SANTIAGO, Marcus Firmino. As origens do judicial review: porque Marbury vs. Madison é apenas um elo em uma longa cadeia. Revista da Ajuris, Porto Alegre, v. 44, n. 143, p. 331-355, dez. 2017. SANTOS, Erika Karine; BEZERRA, Valesca Caetano. Ação afirmativa: a prática da igualdade sob a perspectiva de Flávia Piovesan (Brasil) e Ronald Dworkin (EUA). Revista Fides, Natal, v. 1, n. 1, p. 71-86, fev./jul. 2010.

SANTOS, Michele Carvalho; OLIVEIRA, Leandro Corrêa de. O mito de Marbury v. Madison: a questão da fundação da supremacia judicial. Revista de Investigações Constitucionais, Curitiba, vol. 5, n. 3, p. 325-347, set./dez. 2018.

SILVA, Luiz Fernando Martins da. Considerações sobre o tema "políticas públicas de ação afirmativa para a população negra no Brasil". Revista Direito e Práxis, v. 3, n. 2, p. 122-153, 2011.

SIQUEIRA, Dirceu Pereira; ROSTELATO, Telma Aparecida. Inclusão social, processo coletivo e minorias no ordenamento jurídico brasileiro. Revista USCS, ano X, n. 16, p. 221-237, jan./jun. 2009. Disponível em: http://seer.uscs.edu.br/index.php/revista_direito/article/viewFile/878/731. Acesso em: 06 jul. 2019.

SOUZA NETO, Cláudio Pereira de; SARMENTO, Daniel. Direito constitucional: teoria, história e métodos de trabalho. Belo Horizonte: Fórum, 2012.

STRECK, Lênio Luiz. Jurisdição constitucional e hermenêutica: uma nova crítica do Direito. Porto Alegre: Livraria do Advogado, 2002.

TRINDADE, Augusto Cançado. $\mathbf{O}$ direito internacional em um mundo em transformação. Rio de Janeiro: Renovar, 2002.

VILAS-BOAS, Renata Malta. Ações afirmativas e o princípio da igualdade. Rio de Janeiro: América Jurídica, 2003. 